www.tijdschriftvoorwijsbegeerte.nl

Uitgave: Amsterdam University Press

\title{
Extreme rijkdom eerlijk verdeeld
}

\author{
Stefan Wintein \& Conrad Heilmann
}

ANTW 109 (4): 469-474

DOI: 10.5117/ANTW2017.4.WINT

Robeyns stelt voor om een bovengrens te stellen aan individuele rijkdom: een persoon met meer materiële middelen dan noodzakelijk voor het leiden van een volledig florerend leven, heeft té veel. Zo'n persoon wordt, in de door Robeyns voorgestelde monetaire termen, gekenmerkt door excessief geldbezit. Excessief geld, zo argumenteert Robeyns, vormt een bedreiging voor de democratie en kan bovendien allerhande urgente behoeften bevredigen wanneer het niét in handen van de rijken is. Het moet dus van ze worden afgenomen.

Robeyns situeert haar voorstel in de literatuur omtrent verdelende rechtvaardigheid, waar wordt nagedacht over de faire, of rechtvaardige, verdeling van goederen. Met betrekking tot de huidige verdelende rechtvaardigheidstheorieën werpt Robeyns (p. 412) de vraag op of er 'een nieuwe verdelingsregel moeten worden toegevoegd aan de [bestaande] lijst van mogelijke verdelingsregels, namelijk een maximum of bovengrens.'

Het stellen van een bovengrens is een belangrijke stap in het formuleren van een verdelingsregel, maar het roept ook een nieuwe vraag op: hoe verdelen we het excessieve geld, samenhangend met de bovengrens, op een eerlijke manier? In deze bijdrage laten we zien dat de rijke microeconomische literatuur omtrent fair division (Thomson 2003) de middelen biedt om deze vraag te analyseren. In een ander paper (Heilmann en Wintein 2015) laten we zien dat en hoe deze micro-economische literatuur van belang is voor filosofische theorieën van fairness (Broome 1990).

Gebruikmakend van de fair division literatuur, zullen we enkele modellen opstellen die aspecten uitlichten van, en vragen opwerpen voor, de verdelende rechtvaardigheidstheorie die Robeyns voor ogen heeft. De modellen dienen ter illustratie van de belangrijkste bijdrage van dit paper: het presenteren van een raamwerk waarin de structuur van Robeyns' theorie op heldere en precieze wijze kan worden uitgedrukt. Meer in het bijzonder hopen 
we dat onze bijdrage een eerste aanzet kan zijn tot een vruchtbare discussie omtrent de distributieve gevolgen van Robeyns' interessante voorstel.

\section{$1 \quad$ Het stellen van een bovengrens geeft aanleiding tot een fair division probleem}

Robeyns wil een absolute bovengrens aan individueel geldbezit stellen. Deze bovengrens, laten we haar $R$ noemen, moet volgens Robeyns gelijk genomen worden aan de hoeveelheid geld die nodig is om een volledig florerend leven te leiden. Het stellen van een bovengrens $R$ betekent dat er een bedrag $E$ zal zijn dat afgenomen moet worden van personen met excessief geldbezit. Hoe moeten we $E$ verdelen? Het verdelen van $E$ is niet zelf-evident en geeft aanleiding tot een fair division probleem.

Fair division problemen doen zich voor wanneer een beperkte hoeveelheid van een goed, vaak de estate genoemd, op een faire manier verdeeld moet worden onder een aantal personen. De micro-economische literatuur kent verschillende manieren om fair division problemen te modelleren, bijvoorbeeld als claims problemen of als coöperatieve spelen. Heilmann en Wintein (2015) en Wintein en Heilmann (2017) presenteren een niet-technische inleiding tot deze literatuur.

Om het type fair division probleem dat het stellen van $R$ met zich meebrengt te analyseren, is de claims benadering het meest geschikt. Een claims probleem $\mathrm{C}=(\mathrm{E}, \mathrm{N}, \mathrm{c})$ bestaat uit een estate $E$ en individuen $N$ met claims $c$. Beschouw een maatschappij met drie individuen, Sine, Morten en Sem, die elk 24, 6 en 2 bezitten (de eenheid is niet van belang). Stel dat een volledig florerend leven bereikt wordt met $R=14$.

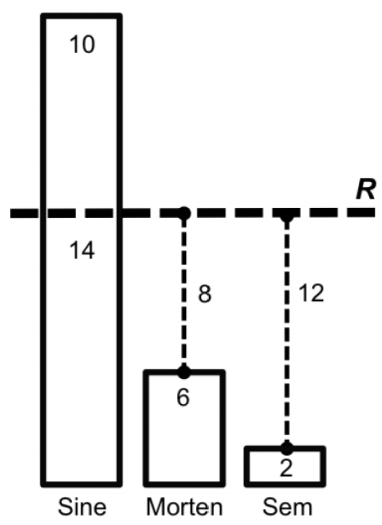

Figuur 1 Excessief geldbezit in een maatschappij met drie personen 
We nemen het excessieve geldbezit van Sine, 10, van haar af. We hebben nu dus $E=10$ om eerlijk te verdelen onder Morten en Sem. Aannemende dat iedereen een claim heeft op een volledig florerend leven, betekent dit dat Morten een claim van 8 heeft en Sem een claim van 12. Wat formeler uitgedrukt hebben we van doen met claims probleem $C=(10$, (Morten, Sem), $(8,12))$.

Robeyns vindt in $R$ een antwoord op de vraag: hoeveel is te veel? Maar zoals we net gezien hebben roept het stellen van $R$ ook een nieuwe vraag op: hoe verdelen we $E$ op een eerlijke manier?

\section{Robeyns' theorie moet $\mathrm{R}$ bepalen, maar ook een verdeelregel voor $E$ specificeren}

Een verdeelregel specificeert hoe de estate in een claims probleem verdeeld moet worden. Er zijn veel verschillende verdeelregels, en ze worden op systematische wijze bestudeerd in de uitgebreide literatuur over claims problemen (Thomson 2003). Een belangrijk onderdeel van deze studies is de axiomatische karakterisering van een verdeelregel: het bepalen van een verdeelregel als de enige regel die een zeker aantal elementaire eigenschappen (axioma's) bezit. Door middel van hun axiomatische karakteriseringen kunnen verdeelregels nauwkeurig bestudeerd, en op vruchtbare wijze met elkaar vergeleken worden.

Drie belangrijke verdeelregels zijn: de proportionele regel $(P)$, de constrained equal awards regel (CEA) de constrained equal losses regel (CEL). Deze regels worden ook wel 'de drie musketiers' genoemd omdat hun axiomatische karakteriseringen sterke gelijkenissen vertonen (Herrero en Villar 2001). Deze gelijkenissen zijn echter niet zichtbaar in de operationele definities van de regels, welke als volgt luiden: $P$ verdeelt de estate simpelweg proportioneel op basis van de claims. $C E A$ stelt 'gelijke' uitbetalingen voor, met dien verstande dat niemand meer kan ontvangen dan zijn claim. CEL stelt voor dat iedereen een 'gelijke' hoeveelheid verliest ten opzichte van zijn claim, met dien verstande dat een individu maximaal zijn gehele claim kan verliezen. Tabel 1 laat zien hoe $E=10$ verdeeld dient te worden volgens deze drie verdeelregels. 
Tabel 1 Verdelingen van $E=10$ volgens $C E A, P$ en $C E L$

\begin{tabular}{l|l|l}
\hline Verdelingen van $E=10 \ldots$ & Morten & Sem \\
...volgens $C E A$ & 5 & 5 \\
$\ldots$ volgens $P$ & 4 & 6 \\
$\ldots$ volgens $C E L$ & 3 & 7 \\
\hline
\end{tabular}

Tabel 2 presenteert de eindverdelingen, die verkregen worden door de initiële bezittingen te combineren met de effecten van het herverdelen van het excessieve geldbezit.

Tabel 2 Eindverdelingen in de maatschappij op basis van CEA, $P$ en CEL

\begin{tabular}{|c|c|c|c|}
\hline Eindverdelingen... & Sine & Morten & Sem \\
\hline ...met CEA & 14 & 11 & 7 \\
\hline met $P$ & 14 & 10 & 8 \\
\hline ...met $C E L$ & 14 & 9 & 9 \\
\hline
\end{tabular}

Tabel 2 laat duidelijk zien dat verschillende verdeelregels verschillende distributieve gevolgen hebben. Verschillende verdeelregels kunnen dus worden ingezet om verschillende doeleinden te realiseren. Robeyns' theorie van verdelende rechtvaardigheid moet uiteindelijk niet alleen $R$ bepalen, maar ook een verdeelregel voor $E$ specificeren. De literatuur over claims problemen, met name omtrent de axiomatische karakterisering van verdeelregels, kan haar hierbij uitstekend van dienst zijn.

$\mathrm{Nu}$ zou men kunnen tegenwerpen dat het stellen van $R$ helemaal geen aanleiding tot een claims probleem geeft: excessief geldbezit moet niet worden verdeeld onder individuen maar moet, bijvoorbeeld, direct worden aangewend om urgente maatschappelijke behoeften te lenigen. Twee reacties daarop. Als eerste denken we dat zo'n 'directe leniging' vaak indirect neerkomt op het oplossen van een impliciet claims probleem; het expliciet maken van het claims probleem heeft in zo'n geval als voordeel dat het te lijf kan worden gegaan met de middelen uit de aangehaalde literatuur. Als tweede merken we op dat het verwerpen van de claims benadering niet wegneemt dat Robeyns' theorie ons zal moeten vertellen hoe, en over wie of wat, $E$ dan wél verdeeld moet worden. Toegegeven, er zijn zekere meerdere manieren om $E$ te verdelen. Maar in het onderstaande willen we 
wijzen op enkele voordelen van het verdelen van $E$ op basis van de claims benadering.

\section{De claims benadering als middel om Robeyns' theorie te evalueren en modificeren}

Als eerste kan de claims benadering ons helpen om, in een bepaalde context, het succes van Robeyns' theorie te evalueren. Robeyns motiveert haar theorie door te argumenteren dat excessief geldbezit de democratie bedreigt, en dat het wegnemen van excessief geldbezit ons in staat stelt om urgente maatschappelijke behoeften te lenigen. De claims benadering helpt ons om te evalueren hoe succesvol een willekeurige $R$ is met betrekking tot het realiseren van deze twee doeleinden. Neem het democratisch argument. In ons voorbeeld met $R=14$ beschikt Sine na de herverdeling niet langer over excessief geld dat haar in staat stelt om politieke invloed te kopen. Maar ze bezit nog steeds substantieel meer in de eindverdeling dan Morten en Sem. Zijn de relatieve verschillen in de eindverdeling niet van dien aard dat er nog steeds politieke invloed gekocht en verkocht zal worden? Zo ja, dan heeft $R=14$ niet het gewenste democratische effect. Neem nu het argument van urgente maatschappelijke behoeften. Stel dat we weten dat de armoedegrens op 8 ligt. Voor $R=14$ betekent dit dat alleen $P$ of $C E L$ alle individuen uit de armoede helpt. Als Robeyns' theorie vergezeld gaat van de $C E A$ regel, dan voldoet $R=14$ dus niet om alle armoede weg te nemen. Op deze wijze biedt de claims benadering ons een raamwerk om het succes van een gegeven $R$, met betrekking tot de motiverende doeleinden voor zo'n $R$, te evalueren.

Als tweede stelt de claims benadering ons in staat om alternatieven voor Robeyns' benadering te onderzoeken. Beschouw Robeyns' voorstel dat maatschappelijke deliberatie over wat een 'volledig florerend leven' is ten grondslag moet liggen aan de bepaling van $R$. Via de claims benadering kunnen we ook andere uitganspunten van deliberatie kiezen om tot een keuze voor een bepaalde R te komen, zoals: de gewenste (on)gelijkheid van de verdeling van middelen in onze maatschappij, of: welke middelen hebben we nodig om urgent maatschappelijke behoeften te leningen, zoals ervoor zorgen dat alle individuen uit de armoede geholpen worden? Laten we dit idee concreet maken via het armoede voorbeeld: we kunnen een 'ondergrens' aan armoede stellen en dan, middels 'backwards engineering', het niveau van $\mathrm{R}$ (en verdeelregel) bepalen zodat ieder individu meer bezit dan deze ondergrens. Deze benadering lijkt in het bijzonder interes- 
sant omdat onze empirische kennis over armoede veel verder reikt dan onze kennis over rijkdom. Maatschappelijke deliberatie over een ondergrens aan armoede zal waarschijnlijk eerder tot een consensus komen dan deliberatie over een bovengrens aan rijkdom.

We hebben laten zien dat Robeyns' theorie aanleiding geeft tot een fair division probleem, welke we geanalyseerd hebben als een claims probleem. De claims benadering leent zich ertoe om Robeyns' theorie en haar distributiegevolgen te specificeren, het succes van de theorie in bepaalde contexten te evalueren, en alternatieven voor de theorie te onderzoeken waarin $R$ bepaald wordt op basis van andere overwegingen dan die van 'een volledig florerend leven'.

\section{Bibliografie}

Broome J (1990) Fairness. Proceedings of the Aristotelian Society 91: 87-101.

Heilmann C, Wintein S (2015) How to be fairer? Synthese 1-25. DOI: 10.1007/s11229-015-0967-y

Herrero C, Villar A (2001) The three Musketeers: four classical solutions to bankruptcy problems. Mathematical Social Sciences 42: 307-28.

Thomson, W (2003) Axiomatic and game-theoretic analysis of bankruptcy and taxation problems: a survey. Mathematical Social Sciences 45(3), 249-297.

Wintein S, Heilmann C (2017) Dividing the indivisible. Politics, Philosophy \& Economics. DOI: $10.1177 / 1470594 \mathrm{X}_{17715248}$

\section{Over de auteurs}

Stefan Wintein is post-doc, verbonden aan de Faculteit der Wijsbegeerte van de Erasmus Universiteit van Rotterdam en doet onderzoek met betrekking tot (filosofische) logica, speltheorie en fairness.

Voor meer informatie, zie zijn website: www.stefanwintein.webklik.nl.

Conrad Heilmann is universitair docent in de filosofie van de economie, verbonden aan de Faculteit der Wijsbegeerte van de Erasmus Universiteit van Rotterdam, en co-directeur van het Erasmus Institute for Philosophy and Economics (EIPE).

Voor meer informatie, zie zijn website: www.cheilmann.org. 